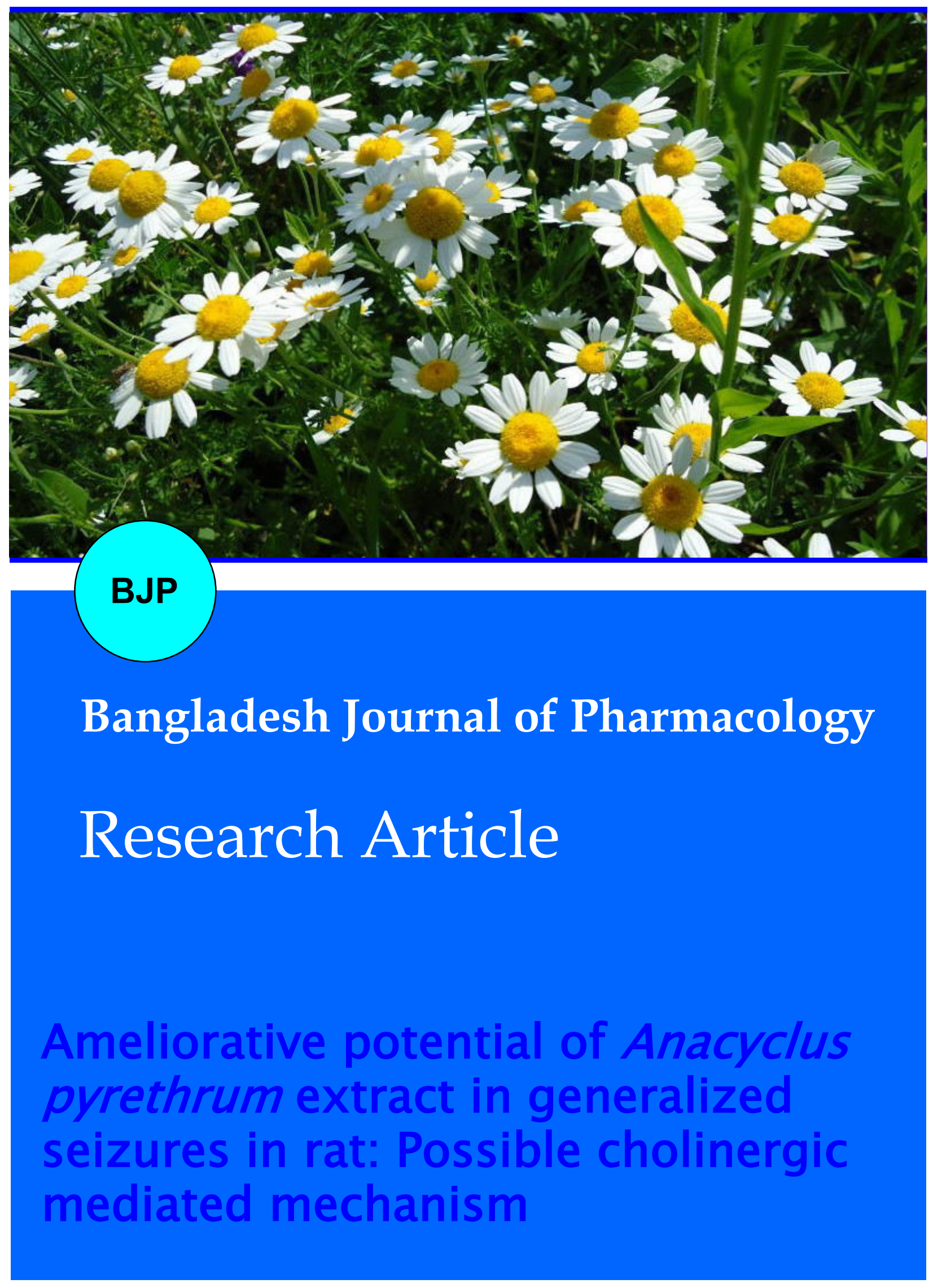




\title{
Ameliorative potential of Anacyclus pyrethrum extract in generalized seizures in rat: Possible cholinergic mediated mechanism
}

\author{
Kenza Bezza, Zineb El Gabbas, Jawad Laadraoui, Mehdi Ait Laaradia, Sara Oufquir and \\ Abderrahman Chait
}

Laboratory of Pharmacology, Neurobiology and Behavior, Semlalia Faculty of Sciences, Cadi Ayyad University, Marrakech, Morocco.

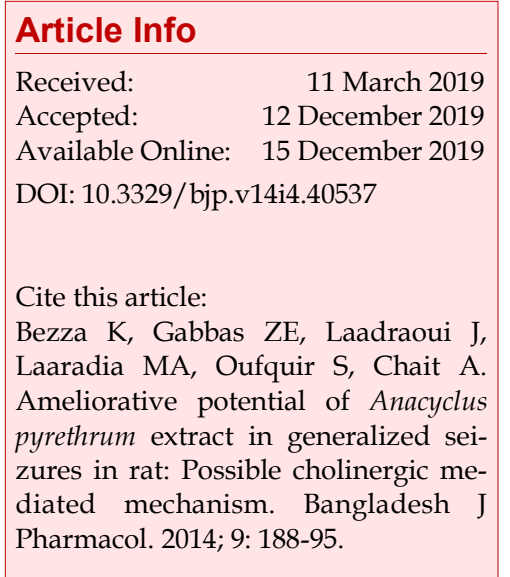

\begin{abstract}
The present study evaluates the anticonvulsant activity of the roots of Anacyclus pyrethrum using pilocarpine-induced experimental model of epilepsy in rat, and to determine its possible anticonvulsant mechanism. Ethanol extract (200 and $400 \mathrm{mg} / \mathrm{kg}$ ) or alkylamides ( 25 and $50 \mathrm{mg} / \mathrm{kg}$ ) was administered orally $45 \mathrm{~min}$ before the injection of pilocarpine-induced (400 $\mathrm{mg} / \mathrm{kg}$ ) seizures. The possible anticonvulsant mechanism was investigated by testing the effect of atropine $(2 \mathrm{~mL} / \mathrm{kg})$ and scopolamine $(1 \mathrm{mg} / \mathrm{kg})$. The scoring of seizure severity, seizures time latency, duration of total seizures and percentage of mortality protection were recorded. Ethanol extract and alkylamides prolonged the time of onset seizure and decreased the duration of seizures compared to control group $(\mathrm{p}<0.001)$. The seizure protection was $100 \%$. The co-administered of ethanol extract of A. pyrethrum and alkylamides with atropine completely abolished the pilocarpine-induced seizures.
\end{abstract}

\section{Introduction}

Epilepsy is known as one of the most prevalent and severe neurological disorders. There are almost one million deaths annually as a consequence of epilepsy (Bell et al., 2014; Hauser et al., 1993).

Antiepileptic drugs are prescribed alone or in combination as a means of curing epilepsy (Hernan and Holmes, 2016). These antiepileptic drugs, in most cases, cause one or more secondary effects (Kaur et al., 2016).

To overcome these problems, several studies conducted in recent years have supported the use of herbal remedies as alternatives. To this end, animal studies have shown that several plants such as Abies webbiana (Parkash et al., 2015), Artemisia persica (Daneshkhah and Setorki, 2019), Carum carvi (Showraki et al., 2016), Citrus sinensis (Citraro et al., 2016), Crocus sativus (Khazdair et al., 2015), Dodonaea viscosa (Karim et al., 2015),
Kalanchoe pinnata (Mora-Pérez and Hernández-Medel, 2016), Laggera aurita (Malami et al., 2016), and Silybum marianum (Waqar et al., 2016) have anticonvulsant effect over experimental models of epilepsy.

Anacyclus pyrethrum, L. (Asteracea) is used to treat a diverse range of diseases. Alkamide derivatives have antiprotozoal activity in vitro (Althaus et al., 2014). It has tonic effect on the nervous system (Nadkarni, 2005) and possesses potent anticonvulsant activity against experimental model of epilepsy (Pahuja et al., 2012; Zaidi et al., 2009). According to Veryser et al. (2016), pellitorine readily absorbed from the intestine and is rapidly penetrated into the blood-brain barrier. Therefore, this compound may have a potential therapeutic role in the treatment of central nervous system diseases. Extracted roots possess antimicrobial, saliva stimulation, local anesthetical, insecticidal, and anti-depressive effects. They are mainly designed to treat rheumatism, 
paralysis, toothache, and epilepsy (Annalakshmi et al., 2012; Boonen et al., 2012). Aqueous extracts are nontoxic and are being used as aphrodisiacs to improve male libido (Sharma et al., 2009; Sujith et al., 2012). The animal study showed that $A$. pyrethrum root extract might produce an antidepressant effect (Badhe et al., 2010). The present study investigates the anticonvulsant activity and possible mechanisms of action of $A$. pyrethrum in pilocarpine-induced seizures in rats.

\section{Materials and Methods}

\section{Animal}

The male Sprague Dawley Sprague rats weighing 180 to $230 \mathrm{~g}$ were placed in a room at a temperature of $22 \pm 2^{\circ}$ $C$ under a cycle of 12:12 hours light:dark with free access to water and food. The animals were provided by the Animal Care Facility of the Faculty of Sciences Semlalia, Cadi Ayyad University, Marrakech, Morocco. Animals were housed in groups of six rats per standard Makrolon cage. The rats were allowed to acclimatize to the housing room conditions for 24 hours before behavioral procedures were initiated. All experiments were performed between 11:00 AM and 5:00 PM. Each animal was used only once to reduce the number of animals used in the experiments.

\section{Plant material and preparation of extracts}

The root of A. pyrethrum was collected in May 2014 from Bin El Ouidan, Morocco. The identification was performed by the Prof. Ouhammou of the Department of Biology, Faculty of Sciences-Semlalia, Cadi Ayyad University. A voucher specimen MARK-10003 was deposited in the Herbarium of the Department of Biology.

The dried roots were crushed to obtain a powder. Then, ethanol solvent $(600 \mathrm{~mL})$ was added to $200 \mathrm{~g}$ powder to obtain the extract using the soxhlet apparatus. Ethanol was completely evaporated using a rotary evaporator. The weight of the concentrated extract was $34.1 \mathrm{~g}$, representing about $17.1 \%$ yield.

\section{Extraction of alkylamides of A. pyrethrum}

The powder (500 g) was extracted with $95 \%$ ethanol in a soxhlet extractor for 20 hours to complete exhaustion. The extract was collected and dried under vacuum using a rotavapor (Stuart RE300, Bibby Scientific, UK).

The ethanol extract was dissolved in distilled water. The aqueous phase was extracted with chloroform. The chloroform extract was collected and dried under vacuum using a rotavapor. The weight of the chloroform extract was $9.2 \mathrm{~g}$ representing about $1.8 \%$ yield.

\section{Acute and subchronic toxicity}

Mice (25--35 g) were equally divided into 10 groups (six animals per group). They were orally treated by gavage with different doses $(200,400,1000,2000,5000 \mathrm{mg} / \mathrm{kg})$ of ethanol extract and (25, 50, 100, 1000, 2000 and 5000 $\mathrm{mg} / \mathrm{kg}$ ) of alkylamides solution for the acute toxicity. Mice were observed during the first 12 hours after administration of the drug to detect signs of toxicity and health.

In the subchronic toxicity, four groups were treated daily with ethanol extract (200 and $400 \mathrm{mg} / \mathrm{kg}$ ) and alkylamides (25 and $50 \mathrm{mg} / \mathrm{kg}$ ) at $10 \mathrm{~mL} / \mathrm{kg}$. A control group received distilled water only. Mice were observed daily and weighted for 14 and 90 days following treatment.

After that period, mice were sacrificed by cervical dislocation, blood was collected and vital organs were immediately collected then weighed, in order to perform biochemical analysis and histological studies.

\section{Histological study}

The vital organs such as liver, heart, lungs, and kidneys were dissected and fixed in $10 \%$ formalin solution for one night. After the organs are subjected to dehydration in a series of grade alcohols and incorporated into paraffin wax. Sections of 4-10 $\mu \mathrm{m}$ thickness were stained with hematoxylin and eosin for histological studies (Kiernan, 1999).

\section{Biochemical analysis}

Biochemical analysis was carried out on the serum of mice. Serum was obtained by centrifugation of blood samples. Creatinine, aminotransferases, creatine phosphokinase and lactate dehydrogenase levels were quantified in the control and treated groups, using the standard method with a biochemical automat (C311 $\mathrm{ROCH})$.

\section{Characterization of A. pyrethrum extract}

The A. pyrethrum root extract was prepared as previously described (Boonen et al., 2012). For the analytical characterization of the extract, it was dissolved in ethanol, vortexed, sonicated for 2 hours and centrifuged for $15 \mathrm{~min}$ at $3,220 \times \mathrm{g}$ at room temperature. A 30:70 water/ethanol $(\mathrm{v} / \mathrm{v})$ solution was prepared, centrifuged again and the supernatant was filtered using a $0.45 \mu \mathrm{m}$ nylon HPLC filter (Whatman).

The high-performance liquid chromatography (Knauer) equipped with a pump (K-1001) and a PDA detector (200-700 UV-Vis) was used to separate and characterize compounds present in A. pyrethrum extract. The analysis was performed with a Eurospher II 100-5, column $(4,6 \times 250 \mathrm{~mm})$, and the temperature was set at $25^{\circ} \mathrm{C}$. The flow rate was $1 \mathrm{~mL} / \mathrm{min}$, the sample volume injected was $2 \mu \mathrm{L}$, and the wavelength of detection was set at $258 \mathrm{~nm}$. 1\% acetic acid in water (A) and acetonitrile (B) mixture were used as the optimal mobile phase for a total running time of $166 \mathrm{~min}$. A gradient with a flow rate of $1.0 \mathrm{~mL} / \mathrm{min}$ was used as follows: $\mathrm{t}=$ 
0 min: 80:20 A:B (v/v); $\mathrm{t}=0-150 \min : 10: 90 \mathrm{~A}: \mathrm{B}(\mathrm{v} / \mathrm{v}) ; \mathrm{t}$ $=150-151$ min: 80:10 A:B (v/v); $\mathrm{t}=151-166$ min: 80:20 $\mathrm{A}: \mathrm{B}(\mathrm{v} / \mathrm{v}) ; \mathrm{t}=166 \mathrm{~min}:$ 80:20 A:B (v/v).

\section{Drug treatment}

Atropine, scopolamine, diazepam and pilocarpine were purchased from the Sigma-Aldrich (France). Atropine $(2 \mathrm{~mL} / \mathrm{kg})$, scopolamine $(1 \mathrm{mg} / \mathrm{kg})$, diazepam $(4 \mathrm{mg} /$ $\mathrm{kg}$ ) and pilocarpine $(400 \mathrm{mg} / \mathrm{kg}$ ) were injected intraperitoneally. The ethanol extract $(200,400 \mathrm{mg} / \mathrm{kg})$ and alkylamides $(25,50 \mathrm{mg} / \mathrm{kg})$ were administered orally.

\section{Treatment}

Animals were divided into 16 groups of six animals each. Pilocarpine (400 mg/kg), pilocarpine plus ethanol extract of A. pyrethrum, pilocarpine plus alkymides, pilocarpine plus ethanol extract and atropine, pilocarpine plus ethanol extract and scopolamine, pilocarpine plus alkylamides and scopolamine, pilocarpine plus alkylamides and atropine, pilocarpine plus atropine, pilocarpine plus scopolamine and pilocarpine plus diazepam. The ethanol extract and alkylamides were administered orally by gavage $45 \mathrm{~min}$, while atropine, scopolamine (cholinergic antagonist) and diazepam were injected $30 \mathrm{~min}$ before injection of pilocarpine. All drugs were orally administered between 9:00 AM and 12:00 AM.

\section{Epileptic behavior testing}

After the intraperitonial injection of pilocarpine to all groups, each rat was placed in the center of the glass cage, and its behavior was observed and monitored within a $90 \mathrm{~min}$ period. The observed epileptic behaviors were ranked as follows: Latency of seizure (min), the latency of tonic-clonic seizure ( $\mathrm{sec}$ ), duration of tonic-clonic seizure (sec), duration of seizures (min), and mortality protection (\%).

The scoring of seizures severity after the injection was recorded during the observation period (90 min) according to the scale: 0 : Normal activity; 1 : Immobility and/or staring; 2: Rigidity, tail extension, head bobbing; 3: Repetitive movements, bilateral pawing, rearing, hind limb tremors; 4: Minor seizure or wobbling, jumping, falling; 5: Tonic-clonic convulsions or multiple and/or occurrence of rating 4; 6: Severe tonic-clonic seizure; 7: Death.

\section{Percentage of seizure protection}

The percentage of protection is calculated using the equation given below. This protection is manifested when the animal returns to normal and gains its normal exploratory behavior.

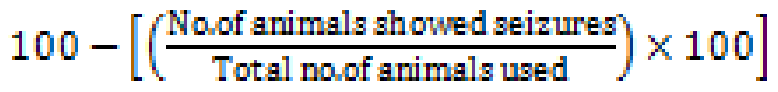

\section{Statistical analysis}

Comparisons between treatment groups and control were performed by one-way analyses of variance (ANOVA) followed by Tukey's HSD test or Dunnett's test, when appropriate. A value of $p<0.05$ was considered to be significant.

\section{Results}

Histopathological and biochemical analysis of toxicity

No visible sign or symptom of toxicity in mice was observed after oral administration of A. pyrethrum ethanol extract. The maximum dose used was $5000 \mathrm{~g} /$ $\mathrm{kg}$. Also, no mortality or significant changes in body weight or organ weight was observed 14 days after administration of ethanol extract.

In the subchronic study, mice received ethanol extract and alkylamides for 90 days with no resulting mortality or signs of toxicity. There were no changes in body and organ weights. Histological examination has not revealed any macroscopic or microscopic tissue lesions.

Creatinine, alanine transaminase, lactate dehydrogenase, aspartate aminotransferase, and creatine phosphokinase levels were also not affected (data not shown).

\section{Scoring of seizure severity}

There was a significant decrease in the seizure score in the different groups of rats pretreated with alkylamides, ethanol extract, (alkylamides plus scopolamine), (ethanol extract of A. pyrethrum plus scopolamine), and diazepam compared to that in the pilocarpine-treated group. Noteworthy, the (alkylamides plus atropine), (ethanol extract of A. pyrethrum plus atropine) has completely abolished the pilocarpine-induced convulsions (Figure 1 (A, B)).

\section{Seizures time latency}

The treatment with ethanol extract of A. pyrethrum (200; $400 \mathrm{mg} / \mathrm{kg}$ p.o), alkylamides (25; $50 \mathrm{mg} / \mathrm{kg}$ ), (alkylamides plus scopolamine), (ethanol extract plus scopolamine), (alkylamides plus atropine), (ethanol extract plus atropine) and, diazepam increased significantly the latency time as compared to the pilocarpine-treated groups $(\mathrm{p}<0.001)$ (Figure $1(\mathrm{C}, \mathrm{D}))$.

\section{Duration of total seizures}

The duration of total seizures was significantly higher in pilocarpine-treated group compared to all treated groups with alkylamides, ethanol extract, (alkylamides plus scopolamine), (ethanol extract plus scopolamine), (alkylamides plus atropine), (ethanol extract plus atropine) and diazepam (Figure $1 \mathrm{E}, \mathrm{F}$ ).

\section{Rate of tonic-clonic seizures}

No tonic-clonic seizure was observed in all the treated groups compared to the pilocarpine-induced convulsion models. 


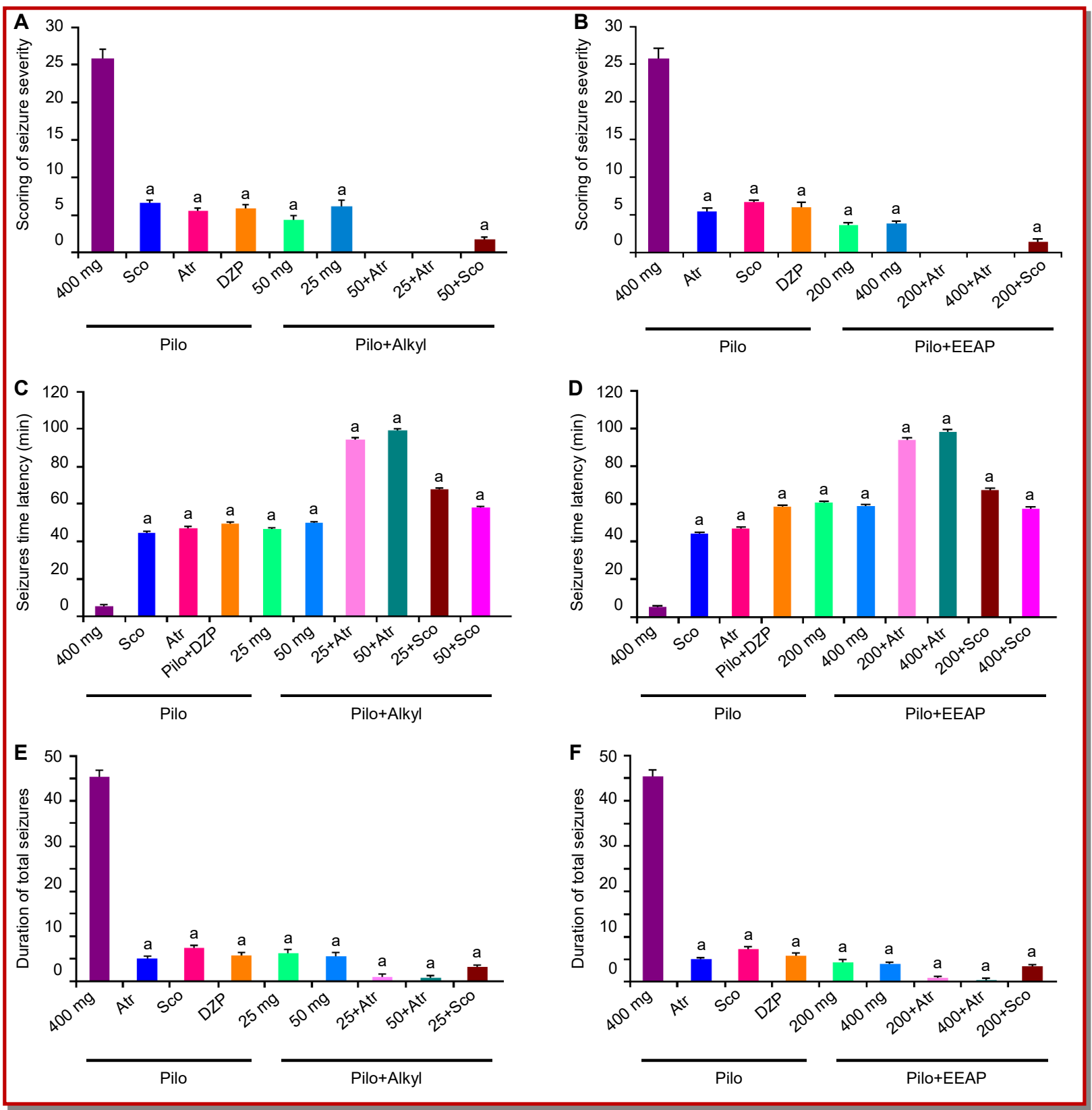

Figure 1: Total seizure scores $(\mathrm{A}, \mathrm{B})$, seizures time latency $(\mathrm{C}, \mathrm{D})$ and Duration of total seizures $(\mathrm{E}, \mathrm{F})$ of all the groups. Effect of treatment with EEAP (200, $400 \mathrm{mg} / \mathrm{kg}$ p.o), Alky (25, $50 \mathrm{mg} / \mathrm{kg}),($ alky+scopolamine), (EEAP+ scopolamine), (alky+atropine), (EEAP+atropine) and, DZP on the pilocarpine induced convulsions. Results are expressed as means \pm S.E.M.. ( $\mathrm{n}=6$ per group).

\section{Percentage protection}

Anticonvulsant studies with the extract showed significant protection in pilocarpine-induced convulsion models (data not shown).

\section{Discussion}

In the present study, root extracts of A. pyrethrum were assessed for their antiepileptic activity in the pilocarpine-based model of epilepsy in rats. The findings showed that the ethanol extract of A. pyrethrum and alkylamides significantly reduced the duration of seizures and increased the latency period of pilocarpineinduced seizures in rats. These effects could be related to the extract effect on cholinergic receptors since the same effects were significantly reported using cholinergic receptor antagonists.

Pilocarpine is commonly considered as cholinomimetic drug widely used to induce convulsions in rodents. These seizures mimic the temporal lobe epilepsy in humans (Turski et al., 1989). The administration of a single dose of pilocarpine $(400 \mathrm{mg}$ ) lead to induce status epilepticus in $83 \%$ of animals and mortality rate was 
100\% (Jope and Morrisett, 1986). The higher dose of pilocarpine produced motor limbic seizures more rapidly in the animals (Curia et al., 2008). In the pilocarpine model, which is a muscarinic agonist, the cholinergic receptor activation is involved in the onset of seizures (Turski et al., 1989). $\mathrm{M}_{1}$ Muscarinic acetylcholine receptors (mAChRs) are implied in the pilocarpine induced seizures generation (Bymaster et al., 2003; Hamilton et al., 1997). Interestingly, Curia et al. (2008) noted that $\mathrm{M}_{1}$ receptors knockout mice were incapable of developing epileptic seizures in response to pilocarpine. In this model, spontaneous seizure activity and neuronal loss are due to seizure-induced glutamate release (Clifford et al., 1987; Jope and Morrisett, 1986). Moreover, pilocarpine is well-known to induce seizures, can also cause pro-inflammatory action in the brain, the study by Marchi et al. (2007) suggests that pilocarpine caused acute peripheral pro-inflammatory changes that lead to a leakage of the blood-brain barrier before the occurrence of the epileptic state (Nicola, 2007).

In the current study, oral administration of ethanol extract of A. pyrethrum and alkylamides as well as atropine and scopolamine produced a significant anticonvulsant effect and reduced the seizure severity, increased the latency time of seizures, also note that, the duration of total seizures was higher in pilocarpine model compared to the treated groups with A. pyrethrum. Thus, the extract produced complete protection against pilocarpine model. In addition to anticonvulsant studies, A. pyrethrum extract was also screened for its acute and subchronic toxicity; it did not produce any behavioral abnormalities or mortality. Manouz et al. (2017) reported that the phytochemical screening of $A$. pyrethrum revealed the presence of flavonoids, alkaloids, terpenoids, tannins and saponins. The studies carried by Paramdeep et al. (2014) found out that alkaloids, flavonoids, terpenoids, saponins, and coumarins enhance gamma amino butyric acid (GABA) transmission. On the other hand, the co-administered of ethanol extract of $A$. pyrethrum and alkylamides with atropine which is an antagonist of muscarinic receptors has completely abolished the pilocarpine-induced seizures, this may suggest the cholinergic involvement in the actions of ethanol extract of A. pyrethrum and alkylamides. In addition, Jo et al., (2002) showed that, at the cellular level, stimulation of mAChRs and nicotinic acetylcholine receptor (nAChRs) on lateral hypothalamic (LH) neurons decreased and increased GABA release, respectively. This may lead us to suggest that, the blockade of muscarinic receptors by atropine as well as scopolamine could induce an increase of GABA.

Several studies have been focused on the central nervous system activities of $A$. pyrethrum extracts. The anticonvulsant effect was demonstrated against maximal electroshock induced convulsions in mice (Iswarya Devi, 2013). Fard and Shojaii, (2013) had also found that the A.pyrethrum extract in mice showed anticonvulsant and myorelaxation activities. Earlier studies suggest that maximal electroshock and pentylenetetrazol might maintain their convulsive effects by inhibiting the activity of gamma amino butyric acid at GABA-A receptors (De Sarro et al., 1999; Vijayalakshmi et al., 2011). Pahuja et al. (2012) and Zaidi et al. (2009) had shown that A. pyrethrum extract has anti-epileptogenic effects on maximal electroshock and pentylenetetrazol models. This result is in agreement with the previously reported findings. According to these data and the present findings, it can be suggested that the anticonvulsant effect of the plant is probably mediated by different mechanisms or different molecules which may act individually or in synergy.

On the other hand, it is well established, that during single prolonged seizures or the induction of recurrent short seizures by chemoconvulsants or electrical stimulation in adult rats and mice, cause the rapid release of inflammatory mediators in areas of the brain where convulsive activity begins and spreads (Aronica et al., 2007; Fabene et al., 2010; Ravizza et al., 2010; Vezzani et al., 2000).

There have also been reports that during seizures, cyclooxygenase-2 (COX-2) is rapidly mediated in the main neurons of the forebrain, including hippocampal pyramidal cells and dentate granulate cells (Ciceri et al., 2002; Marcheselli and Bazan, 1996; Sandhya et al., 1998; Serrano et al., 2011; Takemiya et al., 2006; Yamagata et al., 1993). Furthermore, chemical analysis of the roots of A. pyrethrum showed that they mainly accumulate alkylamides (Zaidi et al., 2013) with an N-isobutylamide alkaloid, called pellitorine as the major active constituent. Furthermore, Crombie (1954) has isolated dodeca-2E,4E-dienoic acid isobutylamide (pellitorine) from A. pyrethrum and Cech et al., (2010) have noted that the identical root component which is pellitorine of Echinacea purpurea was responsible for immunomodulatory effects. As a result, plasma protein levels of certain pro-inflammatory cytokines (IL-8 and IL-6) will decrease, as well the expression of anti-inflammatory molecules such as IL-10. Interestingly, the alkylamides from A. pyrethrum extracts act as an inhibitor of cyclooxygenase (COX) and 5-lipoxygenase (LOX) enzymes (Rimbau et al., 1999). Based on all these data and current findings, it can be suggested that $A$. pyrethrum could act as antiepileptogenic by inhibiting of COX-2 and its ability to decrease certain pro-inflammatory as well.

\section{Conclusion}

A. pyrethrum possesses significant anticonvulsant activity which is abolished by atropine, and thus suggests that the possible mechanism may be mediated through cholinergic pathway. Furthermore, the anticonvulsant action of A. pyrethrum is due to its anti- 
inflammatory properties.

\section{Ethical Issue}

In this study, all animal procedures were in strict accordance with the guidelines of the European Council Directive (EU2010/63). Care was taken to minimize the number of animals used for the experiments. All efforts have been made to limit animal suffering. All efforts were made to minimize any animal suffering, and the study met the ethical standards and approvals of the Council Committee of the research laboratories of the Faculty of Sciences, Cadi Ayyad University of Marrakech.

The acute and subchronic toxicity study was conducted according to the Organization for Economic Cooperation and Development (OECD) guideline No. 423 (OECD, 2001), where the $5,000 \mathrm{mg} / \mathrm{kg}$ limit test dose was used.

\section{Conflict of Interest}

We wish to confirm that there are no known conflicts of interest associated with this publication and there has been no significant financial support for this work that could have influenced its outcome.

\section{Acknowledgement}

We thank Mr. Abderrazak Regragui for the expert animal handling required in this study.

\section{References}

Althaus JB, Kaiser M, Brun R, Schmidt TJ. Antiprotozoal activity of Achillea ptarmica (Asteraceae) and its main alkamide constituents. Molecules 2014; 19: 6428-38.

Annalakshmi R, Uma R, Chandran GS, Muneeswaran A. A treasure of medicinal herb: Anacyclus pyrethrum: A review. Indian J Drugs Dis. 2012; 1: 59-67.

Aronica E, Boer K, van Vliet EA, Redeker S, Baayen JC, Spliet WGM, van Rijen PC, Troost D, Lopes da Silva FH, Wadman WJ, Gorter JA. Complement activation in experimental and human temporal lobe epilepsy. Neurobiol Dis. 2007; 26: 497511

Badhe S, Badhe R, Ghaisas M, Chopade V, Deshpande A. Evaluations of antidepressant activity of Anacyclus pyrethrum root extract. Int J Green Pharm. 2010; 4: 79.

Bell GS, Neligan A, Sander JW. An unknown quantity: The worldwide prevalence of epilepsy. Epilepsia 2014; 55: 958-62.

Boonen J, Bronselaer A, Nielandt J, Veryser L, De Tré G, De Spiegeleer B. Alkamid database: Chemistry, occurrence and functionality of plant $\mathrm{N}$-alkylamides. J Ethnopharmacol. 2012; 142: 563-90.

Bymaster FP, Carter PA, Yamada M, Gomeza J, Wess J, Hamilton SE, Nathanson NM, McKinzie DL, Felder CC. Role of specific muscarinic receptor subtypes in cholinergic parasympathomimetic responses, in vivo phosphoinositide hydrolysis, and pilocarpine-induced seizure activity. Eur J Neurosci. 2003; 17: 1403-10.

Cech NB, Kandhi V, Davis JM, Hamilton A, Eads D, Laster SM. Echinacea and its alkylamides: Effects on the influenza Ainduced secretion of cytokines, chemokines, and PGE2 from RAW 264.7 macrophage-like cells. Int Immunopharmacol. 2010; 10: 1268-78.

Ciceri P, Zhang Y, Shaffer AF, Leahy KM, Woerner MB, Smith WG, Seibert K, Isakson PC. Pharmacology of celecoxib in rat brain after kainate administration. J Pharmacol Exp Ther. 2002; 302: 846-52

Citraro R, Navarra M, Leo A, Donato Di Paola E, Santangelo E, Lippiello P, Aiello R, Russo E, De Sarro G. The anticonvulsant activity of a flavonoid-rich extract from orange juice involves both NMDA and GABA-benzodiazepine receptor complexes. Molecules 2016; 21: E1261.

Clifford DB, Olney JW, Maniotis A, Collins RC, Zorumski CF. The functional anatomy and pathology of lithium-pilocarpine and high-dose pilocarpine seizures. Neuroscience 1987; 23: 953-68.

Crombie L. Isolation and structure of an N-isobutyldienediynamide from pellitory (Anacyclus pyrethrum DC.). Nature 1954; 174: 832-33.

Curia G, Longo D, Biagini G, Jones RSG, Avoli M. The pilocarpine model of temporal lobe epilepsy. J Neurosci Methods. 2008; 172: 143-57.

Daneshkhah M, Setorki M. Effect of Artemisia persica on seizure severity and memory and learning disorders in pentylenetetrazole-kindled mice. Bangladesh J Pharmacol. 2019; 14: 3644 .

De Sarro A, Cecchetti V, Fravolini V, Naccari F, Tabarrini O, De Sarro G. Effects of novel 6-desfluoroquinolones and classic quinolones on pentylenetetrazole-induced seizures in mice. Antimicrob Agents Chemother. 1999; 43: 1729-36.

Fabene PF, Bramanti P, Constantin G. The emerging role for chemokines in epilepsy. J Neuroimmunol. 2010; 224: 22-27.

Fard MA, Shojaii A. Efficacy of Iranian traditional medicine in the treatment of epilepsy. Biomed Res Int. 2013; 2013: 692751.

Hamilton SE, Loose MD, Qi M, Levey AI, Hille B, McKnight GS, Idzerda RL, Nathanson NM. Disruption of the m1 receptor gene ablates muscarinic receptor-dependent $M$ current regulation and seizure activity in mice. Proc Natl Acad Sci USA. 1997; 94: 13311-16.

Hauser WA, Annegers JF, Kurland LT. Incidence of epilepsy and unprovoked seizures in Rochester, Minnesota: 19351984. Epilepsia 1993; 34: 453-58.

Hernan AE, Holmes GL. Antiepileptic drug treatment strategies in neonatal epilepsy. Prog Brain Res. 2016; 226: 179-93.

Iswarya Devi AJ. Anti-convulsant effect of ethanol extract of Ananyclus pyrethrum root 1. Int J Chem Pharm Sci. 2013; 4: 15 -18 .

Jo YH, Talmage DA, Role LW. Nicotinic receptor-mediated effects on appetite and food intake. J Neurobiol. 2002; 53: 618 -32 . 
Jope RS, Morrisett RA. Neurochemical consequences of status epilepticus induced in rats by coadministration of lithium and pilocarpine. Exp Neurol. 1986; 93: 404-14.

Karim N, Irshad S, Khan I, Mohammad A, Anis I, Shah MR, Khan I, Chebib M. GABA A receptor modulation and neuropharmacological activities of viscosine isolated from Dodonaea viscosa (Linn). Pharmacol Biochem Behav. 2015; 136: 6472.

Kaur D, Pahwa P, Goel RK. Protective effect of nerolidol against pentylenetetrazol-induced kindling, oxidative stress and associated behavioral comorbidities in mice. Neurochem Res. 2016; 41: 2859-67.

Khazdair MR, Boskabady MH, Hosseini M, Rezaee R, Tsatsakis AM. The effects of Crocus sativus (saffron) and its constituents on nervous system: A review. Avicenna J Phytomed. 2015; 5: 376-91.

Kiernan JA. Histological and histochemical methods: Theory and practice. 3rd ed. Australia, English Book Illustrated, 1999.

Malami S, Kyari H, Danjuma NM, Ya'u J, Hussaini IM. Anticonvulsant properties of methanol leaf extract of Laggera aurita Linn. F. (Asteraceae) in laboratory animals. J Ethnopharmacol. 2016; 191: 301-06.

Manouz H, , Bouchatta O, Gadhi C, Bennis M, Sokar Z, BaM'hamed S. Anti-inflammatory, antinociceptive, and antioxidant activities of methanol and aqueous extracts of Anacyclus pyrethrum roots. Front Pharmacol. 2017; 8: 598.

Marcheselli VL, Bazan NG. Sustained induction of prostaglandin endoperoxide synthase-2 by seizures in hippocampus: Inhibition by a platelet-activating factor antagonist. J Biol Chem. 1996; 271: 24794-99.

Marchi N, Oby E, Batra A, Uva L, De Curtis M, Hernandez $\mathrm{N}$, Van Boxel-Dezaire A, Najm I, Janigro D. In vivo and in vitro effects of pilocarpine: Relevance to ictogenesis. Epilepsia 2007; 48: 1934-46.

Mora-Pérez A, Hernández-Medel MR. Anticonvulsant activity of ethanol extract from Kalanchoe pinnata Lam. stems and roots in mice: A comparison to diazepam. Neurologia 2016; 31: 161-68.

Nadkarni KM. Indian medicinal plants and drugs with their medicinal properties and uses. Vol I. Mumbai, Pop. Prakashan, 2005, pp 277-78.

Nicola M. In vivo and in vitro effects of pilocarpine: Relevance to ictogenesis. Epilepsia 2007; 48: 1934-46.

Pahuja M, Mehla J, Reeta KH, Joshi S, Gupta YK. Root extract of Anacyclus pyrethrum ameliorates seizures, seizure-induced oxidative stress and cognitive impairment in experimental animals. Epilepsy Res. 2012; 98: 157-65.

Paramdeep S, Damanpreet S, Rajesh KG. Phytoflavonoids: Antiepileptics for the future. Int J Pharm Pharm Sci. 2014; 6: 51-66.

Parkash O, Kumar D, Kumar S. Screening of methanol extract and ethyl acetate fraction of Abies webbiana Lindl. for neuropharmacological activities. Indian J Pharm Sci. 2015; 77: $536-41$

Ravizza T, Balosso S, Aronica E, Vezzani A. Epilepsy: Mecha- nisms, models, and translational perpsectives. 2010.

Rimbau V, Cerdan C, Vila R, Iglesias J. Anti-inflammatory activity of some extracts from plants used in the traditional medicine of North-African countries (II). Phytother Res. 1999; 13: 128-32.

Sandhya TL, Ong WY, Horrocks LA, Farooqui AA. A light and electron microscopic study of cytoplasmic phospholipase A2and cyclooxygenase-2 in the hippocampus after kainate lesions. Brain Res. 1998; 788: 223-31.

Serrano GE, Lelutiu N, Rojas A, Cochi S, Shaw R, Makinson CD, Wang D, FitzGerald GA, Dingledine R. Ablation of cyclooxygenase-2 in forebrain neurons is neuroprotective and dampens brain inflammation after status epilepticus. J. Neurosci. 2011; 31: 14850-60.

Sharma V, Thakur M, Chauhan NS, Dixit VK. Evaluation of the anabolic, aphrodisiac and reproductive activity of Anacyclus pyrethrum DC in male rats. Sci Pharm. 2009; 77: 97110.

Showraki A, Emamghoreishi M, Oftadegan S. Anticonvulsant effect of the aqueous extract and essential oil of Carum carvi L. seeds in a pentylenetetrazol model of seizure in mice. Iran J Med Sci. 2016; 41: 200-08.

Sujith K, Darwin R, Suba V. Toxicological evaluation of ethanolic extract of Anacyclus pyrethrum in Albino Wistar rats. Asian Pacific J Trop Dis. 2012; 2: 437-41.

Takemiya T, Maehara M, Matsumura K, Yasuda S, Sugiura H, Yamagata K. Prostaglandin E2 produced by late induced COX-2 stimulates hippocampal neuron loss after seizure in the CA3 region. Neurosci Res. 2006; 56: 103-10.

Turski L, Ikonomidou C, Turski WA, Bortolotto ZA, Cavalheiro EA. Review: Cholinergic mechanisms and epileptogenesis. The seizures induced by pilocarpine: A novel experimental model of intractable epilepsy. Synapse 1989; 3: $154-71$.

Veryser L, Taevernier L, Joshi T, Tatke P, Wynendaele E, Bracke N, Stalmans S, Peremans K, Burvenich C, Risseeuw M, De Spiegeleer B. Mucosal and blood-brain barrier transport kinetics of the plant $\mathrm{N}$-alkylamide spilanthol using in vitro and in vivo models. BMC Complement Altern Med. 2016; 16: 177.

Vezzani A, Moneta D, Conti M, Richichi C, Ravizza T, De Luigi A, De Simoni MG, Sperk G, Andell-Jonsson S, Lundkvist J, Iverfeldt K, Bartfai T. Powerful anticonvulsant action of IL-1 receptor antagonist on intracerebral injection and astrocytic overexpression in mice. Proc Natl Acad Sci USA. 2000; 97: 11534-39.

Vijayalakshmi A, Ravichandiran V, Anbu J, Velraj M, Jayakumari S. Anticonvulsant and neurotoxicity profile of the rhizome of Smilax china Linn. in mice. Indian J Pharmacol. 2011; 43: 27-30.

Waqar H, Khan H, Anjum A. Antiepileptic potential of Silybum marianum seeds in pentylenetetrazol-induced kindled mice. Bangladesh J Pharmacol. 2016; 11: 603-09.

Yamagata K, Andreasson KI, Kaufmann WE, Barnes CA, Worley PF. Expression of a mitogen-inducible cyclooxygenase in brain neurons: Regulation by synaptic activity 
and glucocorticoids. Neuron 1993; 11: 371-86.

Zaidi SMA, Pathan SA, Jain GK, Ahmad FJ, Jamil S, Singh S, Khar RK. Anticonvulsant and neuropharmacological studies of Anacyclus pyrethrum root extract. Neurosci Res. 2009; 65: S250.
Zaidi SMA, Pathan SA, Singh S, Jamil S, Ahmad FJ, Khar RK. Anticonvulsant, anxiolytic and neurotoxicity profile of aqarqarha (Anacyclus pyrethrum) DC (compositae) root ethanol extract. Pharmacol Pharm. 2013; 4: 535-41.

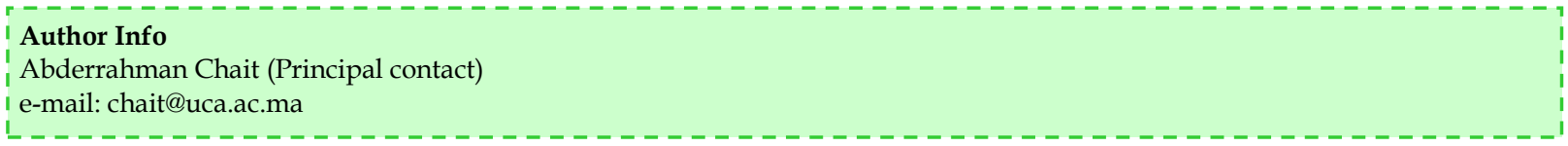

